\title{
Excuse me, doctor: I can still hear you
}

In our patient-authored series, Marije Klein reminds healthcare professionals how important casual conversations can be in creating or destroying patients' confidence and sense of safety. For more information about the series, contact Rosamund Snow, patient editor, rsnow@bmj.com.

\section{Marije Klein}

It was sheer panic that I felt, when I heard the words: "Sleep tight, Miss Klein.”

I should have been more comfortable, lying on the operating table, waiting for my operation. I knew the doctors and assistants around me were very skilled and that I was there for just a minor operation. However, the things that were said just before, and the way they were said, wiped away all the faith I had. All that was left was the panic.

A little more than three years ago, I was 38 years old, busy meeting deadlines as a television journalist. I was also taking care of my three children, and I was very much in love with my boyfriend. Life was smiling at me.

In fewer than three weeks though, I was diagnosed as having breast cancer, learnt that I might possibly die soon, and had to tell my children that they might lose their mother.

I probably don't need to tell you that these were the most disturbing weeks of my life. But what happened afterwards was just as important. I slowly regained trust. I was getting back faith that I would survive, just as long as I was getting the right medication, the right treatment, but most of all just as long as the right healthcare professionals took care of me.

The most important thing I wanted from my doctors during this time was to be able to trust them. My health, and maybe even my life, was in their hands. Luckily many of the healthcare professionals I met, maybe even every one of them, were reliable. Most of the doctors listened carefully to my needs, told me about options, and gave me the feeling that we were in this challenge together. When people (with knowledge of medicine) make you feel that you are not alone, it makes you grateful and gives you hope and strength.

However; some of them scared me to death with their complaining and grumbling. This was what caused me to panic - it made me think there was something wrong and therefore that I was in danger. One example is the anesthetist who was responsible for me during that minor operation. I was already lying on the operating table when he walked in-feeling very vulnerable and somewhat scared, of course. But as I trusted the rest of the people in the operation room, I could handle the suspense.

This anaesthetist however did not start as I expected him to, by shaking my hand or saying hello, but by asking why the drip was in my left arm, instead of in my right. Somebody explained to him that I had a risk of oedema because of earlier operations. The anesthetist turned to a colleague and asked in a firm tone "why the hell" did he not know about this.

Because I presumed it must have been written in my notes, it reduced my faith in him, his colleagues, and all of their skills to almost non-existent. I thought, if this anaesthetist is angry, can he still be focused enough to do his job properly? Are his hands still steady enough to push the right buttons when I am asleep? I was not convinced anymore that this man was calm enough to do his job. And if his annoyance was justified, then maybe his colleagues were not skilled enough.

And this is why I felt sheer panic when I heard the words "Sleep tight, Miss Klein" only a couple of minutes later. All the faith I had in the professionals around me had faded because of the way this one person was speaking to his colleagues. If something had gone wrong, that would have been the last feeling I would ever have had.

Competing interests: I have read and understood BMJ Group policy on declaration of interests and declare the following interests: none.

Cite this as: BMJ 2015;350:h2647

๑ BMJ Publishing Group Ltd 2015 


\section{The bottom line}

- Please remember I am in front of you, beneath you, behind you when you talk to your colleagues. A curtain is not soundproof, and I can still hear you when you are in the corridor. So I can hear you complaining about your boss, grumbling about your working circumstances, talking about the party you all had last night, or reprimanding your staff. When I can hear you doing these things, it makes me feel unsafe. It makes me panic

- Please remember that apologising to me after swearing at your employees won't undo the damage

- Most importantly, please remember that I put my life in your hands, so I really, really want to have faith in your doing your work properly. So that I can walk out of the hospital later and take care of my children again 